\title{
A Study on the Effect of Process and Material Variables on the Hot Stamping Formability of Automotive Body Parts
}

\author{
Kang Ho You ${ }^{1}$ and Heung-Kyu Kim ${ }^{2, *(D)}$ \\ 1 Graduate School of Automotive Engineering, Kookmin University, 77 Jeongneung-ro, Seongbuk-gu, \\ Seoul 02707, Korea; dbrkdgh4@naver.com \\ 2 Department of Automotive Engineering, Kookmin University, 77 Jeongneung-ro, Seongbuk-gu, \\ Seoul 02707, Korea \\ * Correspondence: krystal@kookmin.ac.kr; Tel.: +82-2-910-5611
}

check for updates

Citation: You, K.H.; Kim, H.-K. A Study on the Effect of Process and Material Variables on the Hot Stamping Formability of Automotive Body Parts. Metals 2021, 11, 1029. https://doi.org/10.3390/met11071029

Academic Editor: Badis Haddag

Received: 29 May 2021

Accepted: 24 June 2021

Published: 26 June 2021

Corrected: 28 June 2022

Publisher's Note: MDPI stays neutral with regard to jurisdictional claims in published maps and institutional affiliations.

Copyright: (c) 2021 by the authors. Licensee MDPI, Basel, Switzerland. This article is an open access article distributed under the terms and conditions of the Creative Commons Attribution (CC BY) license (https:// creativecommons.org/licenses/by/ $4.0 /)$.

\begin{abstract}
Hot stamping is a method capable of manufacturing high-strength automotive body parts by inducing a martensitic phase transformation through forming and die quenching after heating a metal sheet into a high temperature austenite phase. However, it is not easy to solve various formability problems occurring in the hot stamping process due to the complexity of the process and material behavior during high temperature forming. In this study, fracture-related forming limits and martensite phase ratio were selected as criteria for evaluating hot stamping formability. First, a hot stamping test was performed on a T-type part that simplified the B-pillar, an automotive body part, and the fracture behavior according to the temperature and thickness of the sheet blank was investigated. Additionally, forming analysis was performed on the hot stamping process of mass-produced B-pillar parts by varying the temperature of the sheet blank, the thickness of the sheet blank, the die-blank friction coefficient, and the strain-rate sensitivity of material among various process and material variables. Based on the analysis results, the effect of each process and material variable on the hot stamping formability of B-pillar parts was quantitatively analyzed. By utilizing the results of this study, it will be possible to solve the formability problem that occurs in the massproduction hot stamping process for automotive body parts and improve the quality of parts in the future.
\end{abstract}

Keywords: hot stamping; formability; forming limit; martensite; B-pillar; forming analysis

\section{Introduction}

As environmental regulations are strengthened around the world, the automobile industry is also actively researching parts manufacturing technology for eco-friendly vehicles. Among them, the hot stamping method is a technology that not only improves fuel efficiency through vehicle weight reduction, but also improves vehicle safety, and is a trend that is more widely applied to the manufacture of vehicle body parts in recent years. In general, hot stamping is a technique in which boron steel is heated and transformed into an austenite phase with excellent formability, and then forming by a press die and quenching in the die are simultaneously performed [1-5]. At this time, the microstructure of the material is transformed into a hard martensite phase due to the rapid cooling effect by the die, and the final strength of the formed part is greatly improved. Due to such advantages, hot stamping is widely applied to vehicle body parts related to safety performance. Therefore, if forming defects such as fracture, neck, and strength decrease occur in parts manufactured by hot stamping, the strength of the product becomes weak and serious problems may occur in the safety of the vehicle. Therefore, it is necessary to identify forming defects or formability problems that may occur in the hot stamping process. The goal of this study is to identify process and material variables that affect various formability problems that may occur in the hot stamping process, and to quantitatively investigate the effect of each variable on formability. 
As for related research trends, Turetta et al. investigated the formability of 22MnB5 material for the hot stamping process [6], and Shao et al. evaluated the formability in hot stamping by applying a biaxial testing system and a new materials model [7]. Dahan et al. studied the formability according to the width of the plate and the initial temperature in the hot stamping process [8], Kusumi and Nomura performed a study on the improvement of the formability according to the coating and the temperature non-uniformity in the hot stamping forming [9]. Windmann et al. investigated the effect of different Al-base coatings en masse by examining the phase formation as a function of coating thickness and Si content at the steel substrate/coating interface [10]. Gorriño et al. determined the interfacial heat transfer coefficient in the industrial range of contact pressure applied during the hot stamping process of boron steel sheets and examined the mechanical properties and microstructure of the parts [11]. Gui et al. investigated the thermo-mechanical behavior of boron steels with and without an Al-Si coating by performing hot tensile tests at various temperature and strain-rate conditions [12]. On the other hand, Kim et al. investigated the problem of the martensite phase transformation according to the heat transfer characteristics and the resulting change in the strength of the parts in the hot stamping process [13].

The criterion mainly used for the evaluation of formability in the stamping operation of metal sheets is the occurrence of fracture, and the forming limit curve (FLC) indicates the strain at which fracture occurs for various deformation modes. Examples of the study on the forming limit in hot stamping or hot forming and the fracture prediction based on it are as follows: Dilmec et al. experimentally investigated the effect of AA2024-T4 sheet thickness and anisotropy on FLC according to ISO 12004-2 standard [14]. Li et al. combined the BBC2005 yield criteria with two hardening laws and M-K (Marciniak and Kuczynski) analysis to show the temperature and strain dependent FLC of 22MnB5 [15]. In addition, $\mathrm{Li}$ et al. investigated the effect of forming temperature and blank thickness on the formability of boron steel 22MnB5 in terms of FLC [16]. In addition to the FLC and strain-based fracture criteria, many energy-based and critical stress-based fracture criteria have been previously developed and studied. Yao et al. showed that first-principle stress is the most important threshold value for tensile fracture of ductile materials using the finite element aided testing (FAT) method for A508-3 and SS316L [17]. Churyumov et al. investigated the change in stress triaxiality according to deformation, and attempted to determine the critical values of the modified Rice and Tracy criteria by considering the stress triaxiality at the moment of fracture under various temperature and strain-rate conditions [18]. Kubík et al. investigated the ductile fracture criteria under low stress triaxialities for aluminum alloy 2024-T351 and AISI 1045 carbon steel, and implemented the calibrated ductile fracture criteria in the user subroutine VUMAT of the commercial finite element code Abaqus [19]. Kim and Kim formulated a damage-based fracture criteria incorporating the temperature and strain-rate effects and predicted the fracture behavior of magnesium alloy sheets [20].

As an example of a study on martensitic phase transformation due to hot stamping, Bariani et al. conducted a phase transformation test as well as formability limit in hot stamping using the Nakajima test [3]. In addition, Kim et al. and Jeon et al. investigated the effect of contact conditions in hot stamping on martensite phase transformation [13,21].

It can be seen from existing studies that it is necessary to consider not only the temperature of the sheet but also the thickness of the sheet in order to accurately predict the fracture or forming limit in hot stamping. Meanwhile, the criterion of formability in hot stamping may include a degree of phase transformation, that is, a martensite phase ratio, related to a desired level of product strength, in addition to the strain when fracture occurs. Therefore, formability in this study is intended to include two criteria: "strain at fracture" and "martensite phase ratio".

Candidates for variables that can affect fracture and phase transformation include not only the sheet temperature and sheet thickness, but also die-blank friction coefficient, dieblank clearance, and material properties. By quantitatively analyzing the fracture behavior 
and the martensite phase ratio of the sheet blank during the hot stamping process according to these various variables, the effect of each variable on the formability is evaluated. The fracture behavior of the sheet in the hot stamping process was indirectly estimated through the thickness strain of the sheet, and the reason for this will be explained later.

In this study, a hot stamping test of a T-type part that simplified the B-pillar, an automotive body part, was performed. From this result, the hot stamping forming limit according to the temperature and thickness of the sheet blank was quantitatively investigated. Based on the forming analysis for the actual B-pillar part, formability evaluation according to variables was then performed. In the analysis of formability, the results from existing researches and the test on T-type parts were used. Through this analysis, the degree of effect of the variable was quantitatively identified, and a method to solve the formability problem during the hot stamping process was suggested.

\section{Effect of Process and Material Variables on Hot Stamping Formability Estimated by T-Type Part Forming Test}

First, a hot stamping forming test was performed on a T-type type component that simulates the main characteristics of the B-pillar, an automotive body part. T-type parts have a simpler shape than B-pillar parts. However, since the forming test of the T-type part can represent the main forming mode occurring in the forming of the B-pillar part, it is possible to analyze the main characteristics occurring in the body part instead of the difficult test using the complicated body part. The shape of the T-type part investigated in this study was designed as shown in Figure 1.
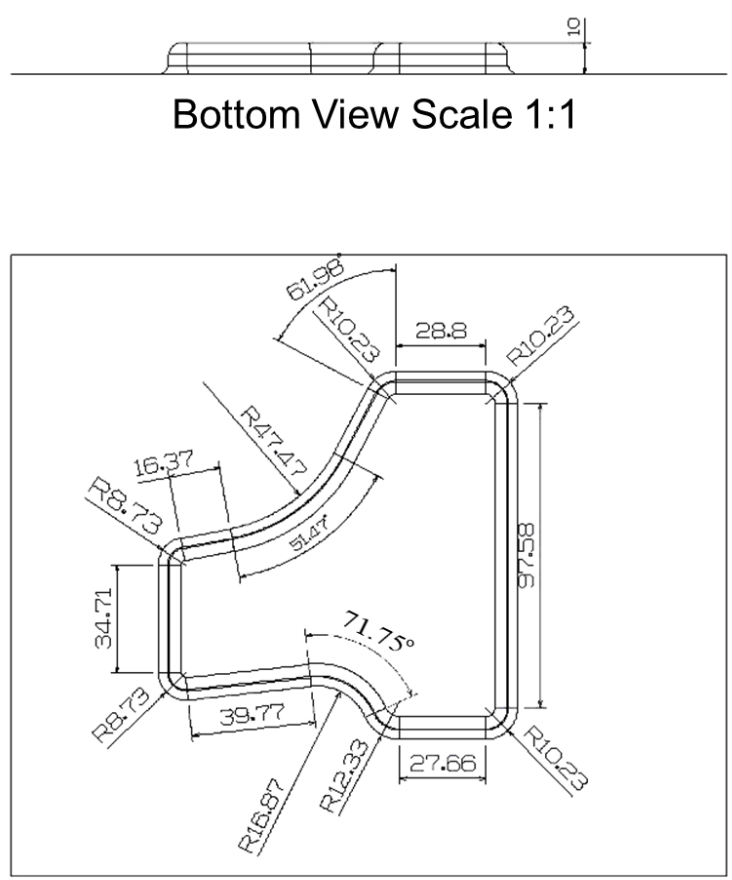

\section{Front View Scale 1:1}

Figure 1. T-type part designed for hot stamping test (unit: $\mathrm{mm}$ ).

The material to be used in the hot stamping test is boron steel (22MnB5) capable of martensitic phase transformation, and has a chemical composition as shown in Table 1. To investigate the effect of the sheet thickness, sheet blanks having two thicknesses of 1 $\mathrm{mm}$ and $1.2 \mathrm{~mm}$ were used. A blank of an appropriate shape as shown in Figure 2 was machined and used for the hot stamping test. In this study, since fracture of the sheet blank must be induced in order to observe the forming limit in hot stamping, the optimization of the blank shape to improve the forming limit was not performed. 
Table 1. Chemical composition of the SABC1470 steel used in the hot stamping test.

\begin{tabular}{ccccccc}
\hline \multicolumn{7}{c}{ Composition (wt.\%) } \\
\hline $\mathrm{C}$ & $\mathrm{Si}$ & $\mathrm{Mn}$ & $\mathrm{P}$ & $\mathrm{S}$ & $\mathrm{B}$ & $\mathrm{Fe}$ \\
0.23 & 0.26 & 1.24 & 0.015 & 0.002 & 0.0023 & Balanced \\
\hline
\end{tabular}

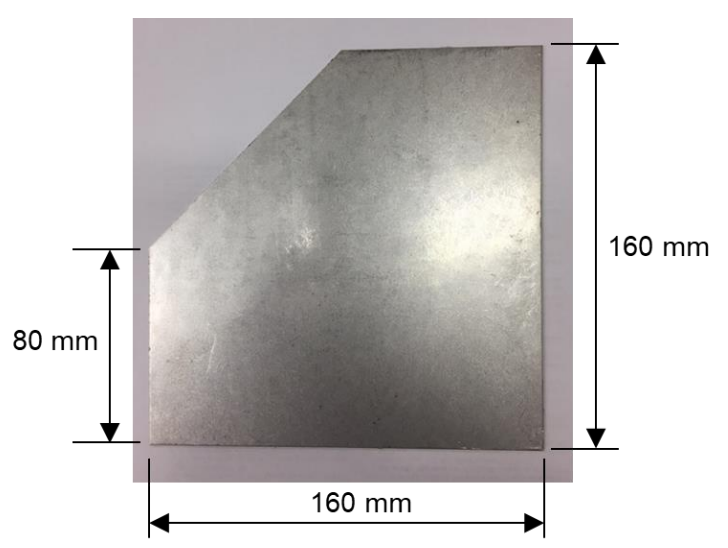

Figure 2. Shape of sheet blank used for hot stamping test of T-type part.

Among various process and material variables, the initial temperature and thickness of the sheet blank were selected as variables to be considered, and the effects of the two variables on the hot stamping forming limit were investigated. There were three candidates for the initial temperature, 900,950 , and $1000{ }^{\circ} \mathrm{C}$. In fact, heating at high temperature such as $1000^{\circ} \mathrm{C}$ can be uneconomical as it can cause oxidation problems in the case of uncoated SABC1470 steel. In this study, however, it was assumed that the temperature-dependent formability did not differ significantly between coated and uncoated steels. Under that assumption, whether the material is coated or uncoated, we examined the formability under various temperature conditions. Meanwhile, two candidates for the initial thickness were $1 \mathrm{~mm}$ and $1.2 \mathrm{~mm}$.

The hot stamping test of T-type parts was performed using the machined sheet blank as shown in Figure 2. The hot stamping die was installed and operated on a 200-ton hydraulic servo press (model: KOMATSU H1F200) with speed profile control. Figure 3 shows the press equipment and the installed die for the hot stamping test of the T-type part. A cooling channel for water cooling was installed in the die to suppress the temperature rise of the die due to repeated contact with the heated blank.

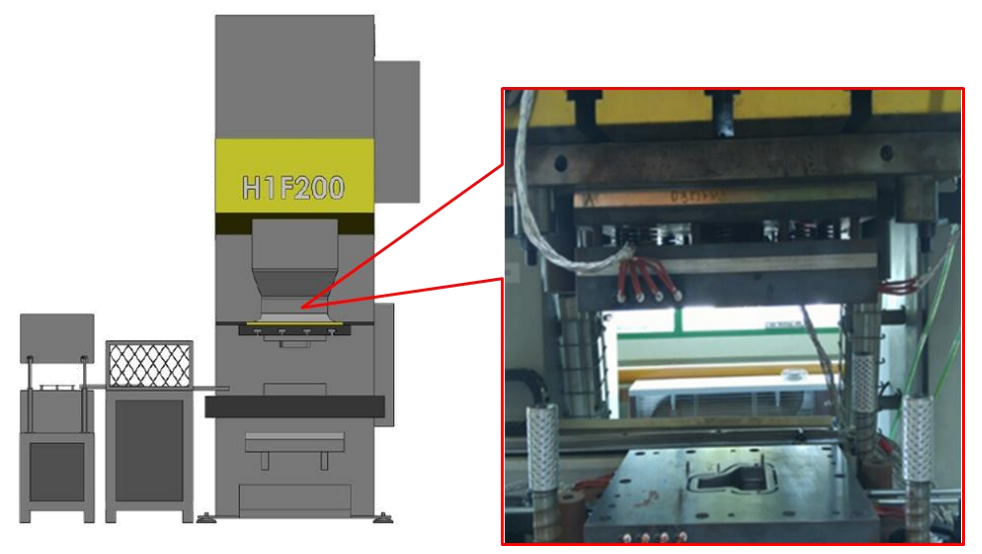

Figure 3. Press equipment and installed die for hot stamping test of T-type parts.

The entire hot stamping process proceeded as follows. The sheet blank was placed in a furnace and heated to one of 900,950 , and $1000{ }^{\circ} \mathrm{C}$ for about $10 \mathrm{~min}$. Through sufficient 
heating, the sheet blank is transformed into an austenite phase with excellent formability. After that, the sheet blank in the furnace was taken out and quickly transferred to the hot stamping die. The transfer process took $7 \mathrm{~s}$. The blanks placed on the hot stamping die were formed to the desired drawing depth by operation of the press. At this time, the punch descending speed of the hot stamping die according to the servo press setting was measured as $10.8 \mathrm{~mm} / \mathrm{s}$. The press machine is not equipped with a load measuring device. Furthermore, the load cell was not installed in the T-type die used in this study due to the structural complexity of the hot stamping die. Thus, the stamping pressure during the actual forming test was not measured. The stamping pressure can be estimated indirectly by performing a forming analysis, although the prediction by forming analysis may differ from the actual stamping pressure measured from the test. The entire hot stamping process can be schematically represented as shown in Figure 4.

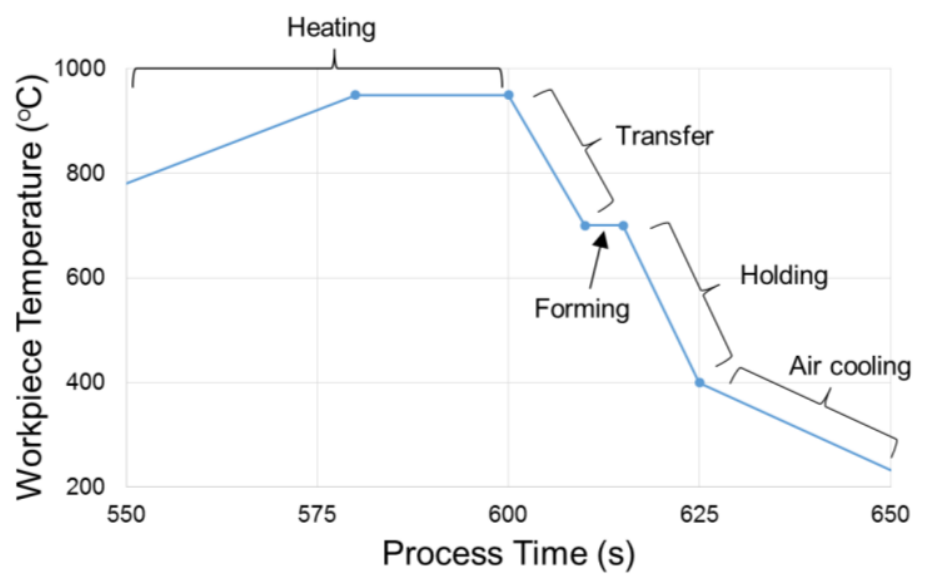

Figure 4. Schematic temperature-time profile of the entire hot stamping test process for T-type parts.

Forming tests were performed for various depths to investigate forming limits. As a result of the test, fracture of the sheet blank was observed within the drawing depth range from 10 to $15 \mathrm{~mm}$. If forming was successful at a small drawing depth, the maximum possible drawing depth was investigated by increasing the drawing depth and retesting.

The hot stamping test of the T-type part was performed while increasing the forming depth by $1 \mathrm{~mm}$. The results can be summarized as shown in Table 2. The formability of T-type parts under two sheet blank thicknesses of $1 \mathrm{~mm}$ and $1.2 \mathrm{~mm}$ and three initial temperature conditions of 900,950 , and $1000{ }^{\circ} \mathrm{C}$ can be compared as follows.

Table 2. Hot stamping test results of T-type parts according to thickness and temperature of sheet blank.

\begin{tabular}{ccccc}
\hline Case & Thickness $(\mathbf{m m})$ & Temperature $\left({ }^{\circ} \mathbf{C}\right)$ & Drawing Depth $(\mathbf{m m})$ & Formability \\
\hline 1 & 1 & 900 & 10 & Crack \\
2 & 1 & 950 & 10 & No defect \\
3 & 1 & 950 & 12 & Crack, Fracture \\
4 & 1 & 950 & 13 & Fracture \\
5 & 1 & 950 & 14 & Fracture \\
6 & 1.2 & 950 & 14 & Neck \\
7 & 1 & 1000 & 10 & No defect \\
8 & 1.2 & 1000 & 14 & No defect \\
9 & 1.2 & 1000 & 15 & Fracture \\
\hline
\end{tabular}

When the sheet blank thickness was $1 \mathrm{~mm}$, the blank heated at $900{ }^{\circ} \mathrm{C}$ was formed without breaking to a drawing depth of $9 \mathrm{~mm}$, and the blank heated at $950{ }^{\circ} \mathrm{C}$ was formed without breaking to a drawing depth of $10 \mathrm{~mm}$. In addition, when the sheet blank thickness was $1.2 \mathrm{~mm}$, the blank heated at a temperature of $950{ }^{\circ} \mathrm{C}$ was formed without breaking 
up to a drawing depth of $13 \mathrm{~mm}$, and the blank heated at a temperature of $1000{ }^{\circ} \mathrm{C}$ was formed without breaking up to a drawing depth of $14 \mathrm{~mm}$. That is, in both sheet blanks of two thicknesses, the higher the heating temperature of the furnace, the higher the forming limit. This trend is consistent with the general tendency of metals with increased ductility at higher temperatures.

Experimental results when the furnace heating temperature was $950{ }^{\circ} \mathrm{C}$ were compared for different sheet blanks. The results showed that a sheet blank with a thickness of $1 \mathrm{~mm}$ was formed without breaking up to a deep drawing depth of $10 \mathrm{~mm}$, and a sheet blank with a thickness of $1.2 \mathrm{~mm}$ was formed without breaking up to a depth of $13 \mathrm{~mm}$ in deep drawing. That is, it can be seen that the forming limit was increased in a sheet blank having a large thickness even though it was heated to the same temperature.

This early fracture phenomenon in the thin sheet blank is presumed to be due to the faster cooling of the thin sheet blank, resulting in a smaller practical forming limit. The faster cooling of the thin sheet blank can be understood from the fact that the thinner the sheet, the lower the heat capacity of the blank.

The formed specimen obtained from the hot stamping test of the T-type part of the sheet blank is shown in Figure 5 according to the initial temperature and the thickness of the sheet blank. It can be seen that forming defects such as neck and fracture occurred mainly at the edge of the part where the deformation was concentrated.

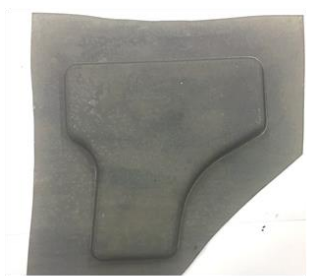

No fracture

- Blank thickness: $1 \mathrm{~mm}$

Heating temperature: $950^{\circ} \mathrm{C}$ - Deep drawing depth: $10 \mathrm{~mm}$
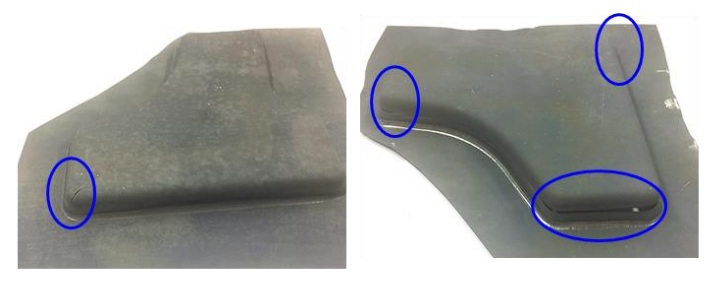

Fracture at side walls and corners

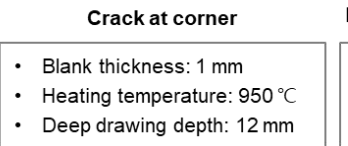

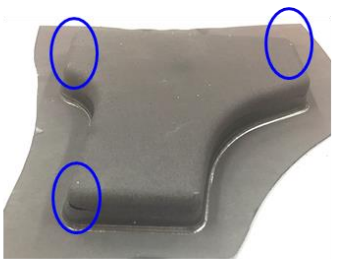

Fracture at corners

- Blank thickness: $1.2 \mathrm{~mm}$

- Heating temperature: $1000^{\circ} \mathrm{C}$ - Deep drawing depth: $15 \mathrm{~mm}$

Figure 5. Shape of formed T-type specimen according to sheet blank thickness and heating temperature condition.

In the part where the fracture or neck occurs, it is difficult to directly measure the thickness strain of the part because the curvature of the shape of the part is large and the local dimensional change is large. As a method of indicating the forming limit in sheet metal forming, the plane strains (major strain and minor strain) for FLC can be measured instead of measuring the thickness strain. However, it is also very difficult to print a grid on the blank surface and measure the grid shape after forming in order to measure the plane strain in high-temperature forming such as hot stamping. For these reasons, many existing studies dealing with warm or hot deep drawing of sheets evaluated the formability based on the drawing depth or the limiting drawing ratio [20,22]. Likewise, the current study also focused on the relative comparison of drawing depth according to temperature and thickness of sheet blank. In order to estimate the strains at fracture, however, we performed a hot stamping analysis of T-type parts. Then, we could obtain the plane strain data at the time of fracture based on the forming analysis. Although we could not directly measure the thickness strain in the forming test, the thickness strain can be estimated from the plane strain data obtained from the forming analysis. Figure 6 shows the major strains and minor strains at the time of fracture obtained from the forming analysis according to the heating temperature of the sheet blank. 


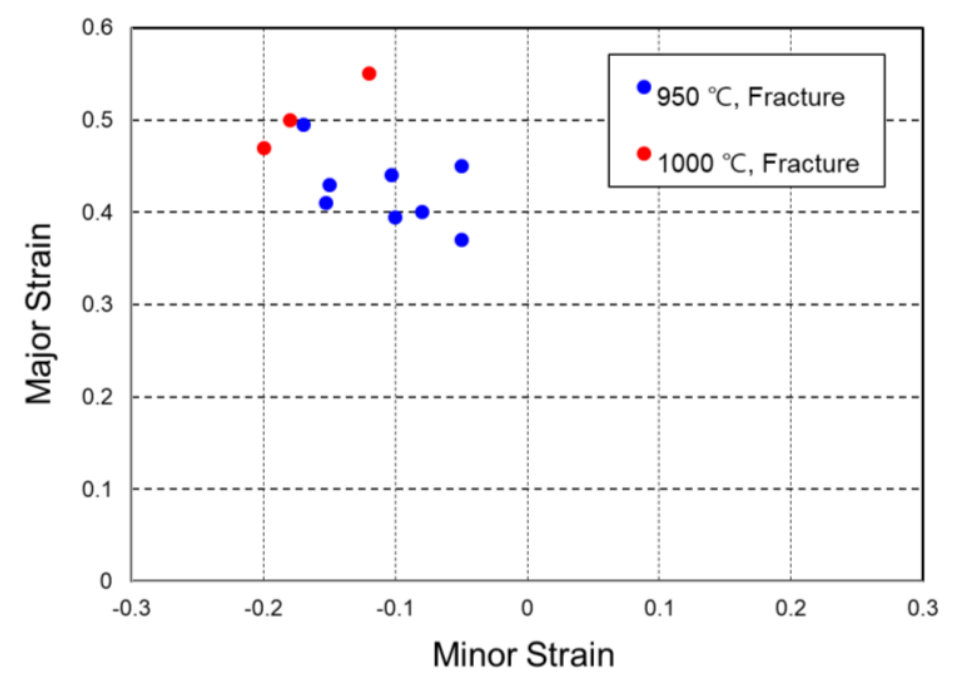

Figure 6. Major strain and minor strain at fracture according to heating temperature of sheet blank obtained from forming analysis corresponding to forming test of T-type part.

\section{Effect of Process and Material Variables on Hot Stamping Formability Estimated by B-Pillar Part Forming Analysis}

Formability evaluation according to process and material variables was performed on a B-pillar part. For this, the DOE (design of experiment) was used and variables to be considered and the level of each variable were set. Since DOE through actual test requires excessive time and cost, DOE based on virtual test through forming analysis was performed. For additional information necessary for determining the formability, the results of the previous T-type experiment were used.

The B-pillar part model used in this study was based on the benchmark model provided by Numisheet 2008, as shown in Figure 7.

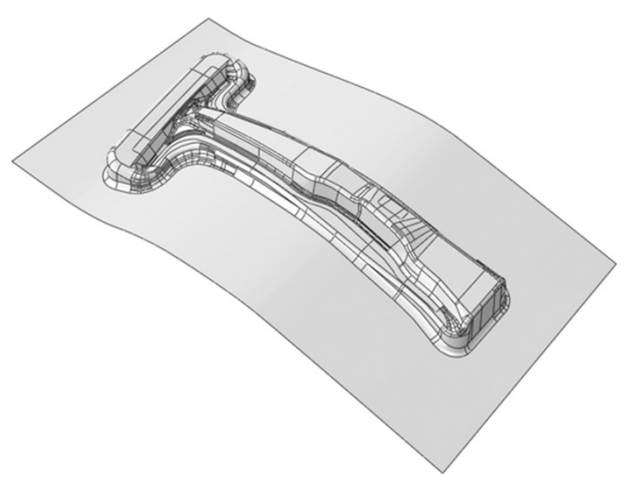

(a)

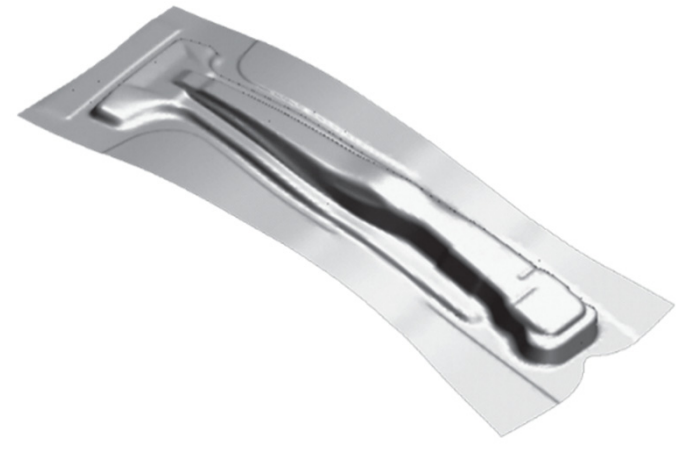

(b)

Figure 7. (a) CAD model of the die for B-pillar part and (b) an example of the formed product.

It is common to judge the sheet press forming limit based on FLC [23,24]. However, for the hot stamping process, which is the subject of this study, it is very difficult to obtain reliable sheet forming limit curve data for numerous materials and process conditions including various temperatures and strain-rates [25]. On the other hand, as a criterion for simple and convenient prediction of sheet fracture in press forming, the thickness strain of the sheet blank can be used instead of the FLC [26,27]. Therefore, in this study, thickness strain was used for convenience as a criterion for predicting the forming limit, which is one of the formability criteria.

The initial temperature and thickness of the sheet blank, which were considered important in the previous T-type part test, were included in the process and material 
variables for the formability evaluation. In addition, the die-blank friction coefficient, which affects the inflow of blanks during forming, was added to the process and material variables to be considered. On the other hand, since hot stamping is performed at a high temperature, the effect of the high-temperature material properties of the sheet blank on the formability cannot be ignored [28,29]. Therefore, among the material properties considered for high temperature conditions, the strain-rate sensitivity, which is known to have a greater effect at high temperatures, was included in the process and material variables to be considered [30,31]. DOE based on full factorial design was performed for the selected material and process variables as described above.

In this study, the degree of influence on the formability defined from the two viewpoints of fracture and martensite phase ratio can be different for each variable, and the degree of effect of each variable needs to be quantitatively determined. So, by analyzing the DOE result based on the forming analysis, the sensitivity, which is the change in formability according to the change of material and process variables, was obtained. From this analysis, it was ascertained which variable has the greatest effect on the formability in the range of the designed variables.

A forming analysis using PAM-STAMP 2015.01 was performed to obtain the formability sensitivity. It is known that PAM-STAMP can provide reliable forming analysis results for various stamping processes including hot stamping processes [32,33]. In simulations using the explicit dynamic finite element code PAM-STAMP, the die was modeled as a rigid body and the sheet blank was modeled as an elastic-plastic shell element. As the forming takes place in a very short time in the whole hot stamping process, for the sake of efficiency, only the deformation was calculated without calculating the heat transfer between the die and the sheet blank for the short forming process. Of course, for the subsequent die quenching process, the heat transfer between the die and the sheet blank was calculated and the phase transformation was estimated based on the Johnson-Mehl-Avrami-Kolmogorov (JMAK) equation and the Koistinen-Marburger (K-M) equation. According to the benchmark results of continuous press hardening of Numisheet 2008, the plastic anisotropy of the sheet can be neglected in hot stamping, so an isotropic model was assumed for the yield function of the sheet blank [34].

Table 3 shows the fixed variable values of the processes and materials used in the B-pillar hot stamping analysis. Considering the mass production process, the press speed was assumed to be $250 \mathrm{~mm} / \mathrm{s}$, and the quenching time was assumed to be $30 \mathrm{~s}$, the point at which the change in the martensite phase ratio almost disappeared. Process variables such as die pad force and holder force were assumed by referring to data from the actual mass production process. The maximum value of the forming force of the die provided by the press equipment was $10 \mathrm{MN}$, and the actual forming force required for the die during the forming process is variable depending on the instantaneous deformation and work hardening of the sheet blank.

Table 3. Fixed values of process and material variables used for B-pillar hot stamping forming analysis.

\begin{tabular}{ccc}
\hline Fixed Values of Process and Material Variables & Unit & Value of Variable \\
\hline Initial temperature of die & ${ }^{\circ} \mathrm{C}$ & 70 \\
Temperature of cooling water & ${ }^{\circ} \mathrm{C}$ & 12 \\
Temperature of air & ${ }^{\circ} \mathrm{C}$ & 20 \\
Convection heat transfer coefficient & $\mathrm{kW} / \mathrm{m}^{2} \mathrm{~K}$ & 0.01 \\
Press speed & $\mathrm{mm} / \mathrm{s}$ & 250 \\
Time for quenching & $\mathrm{s}$ & 30 \\
Punch-die clearance & $\mathrm{mm}$ & 1.2 \\
Die pad force & $\mathrm{MN}$ & 0.8 \\
Holder force & $\mathrm{MN}$ & 0.15 \\
\hline
\end{tabular}


In PAM-STAMP, the interfacial heat transfer coefficient can be expressed as a function of the contact pressure at the interface and the blank-die gap. The interfacial heat transfer coefficient at a contact pressure of $20 \mathrm{MPa}$ was investigated in the literature. Then, the study of Bosetti et al. suggested about $2 \mathrm{~kW} / \mathrm{m}^{2} \mathrm{~K}$ [35], the study of Vrolijk et al. suggested about $2.8 \mathrm{~kW} / \mathrm{m}^{2} \mathrm{~K}$ [33], and the study of Liu et al. suggested about $9 \mathrm{~kW} / \mathrm{m}^{2} \mathrm{~K}$ [36]. Therefore, from the average of the above three values, the interfacial heat transfer coefficient at a contact pressure of $20 \mathrm{MPa}$ could be estimated as $4.6 \mathrm{~kW} / \mathrm{m}^{2} \mathrm{~K}$. Based on this, the interfacial heat transfer coefficient expressed as a function of contact pressure as shown in Figure 8 was applied to this analysis.

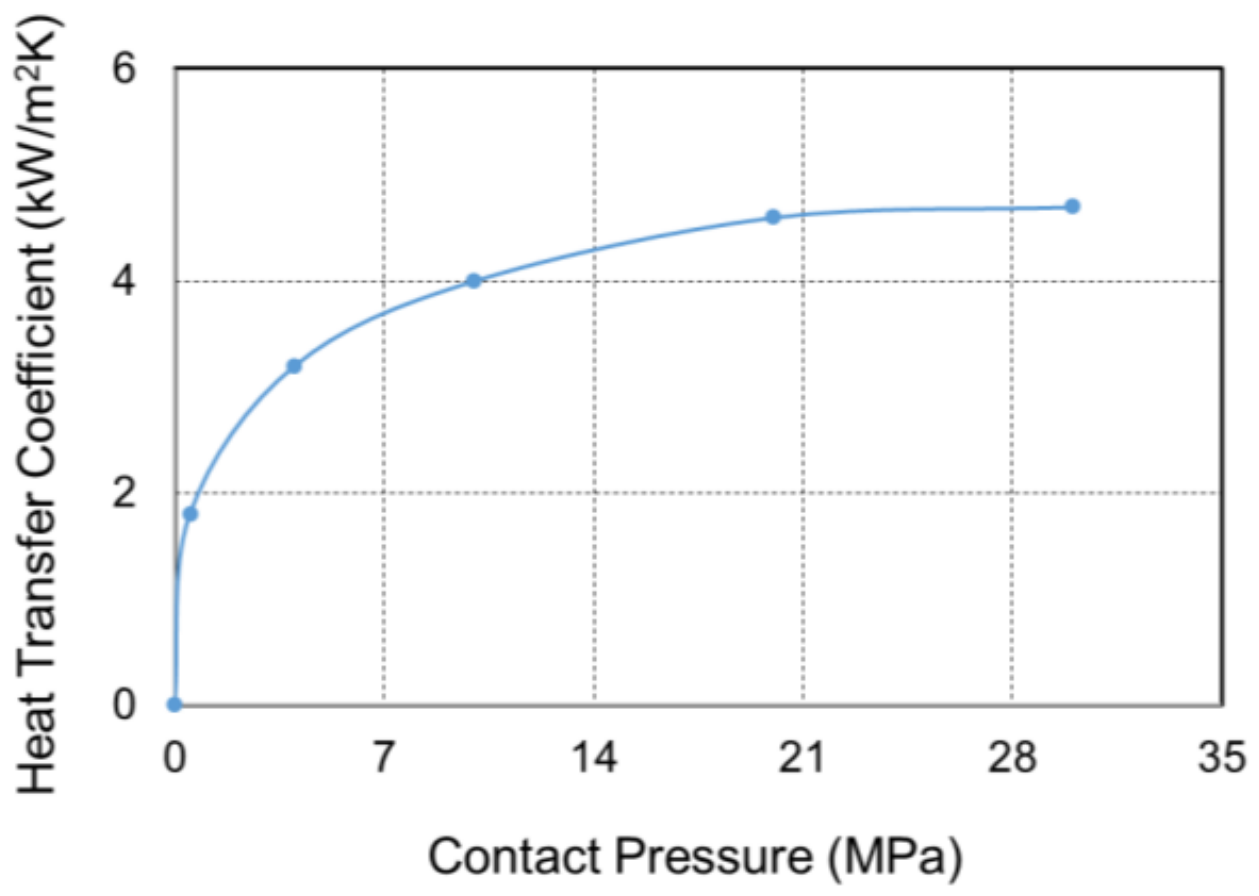

Figure 8. Interfacial heat transfer coefficient expressed as a function of contact pressure for hot stamping analysis using PAM-STAMP.

For the full range stress-strain curve of 22MnB5 material, data provided by PAMSTAMP as shown in Figure 9 were used. Since the material variable includes the strain-rate sensitivity, the stress-strain relation in Figure 9 was modeled as the rate power law and fluctuation was applied for the strain rate sensitivity $m$. If the amount of fluctuation is expressed as $\Delta m$, the stress-strain relation can be expressed as follows.

$$
\bar{\sigma}=K \bar{\varepsilon}^{n} \dot{\bar{\varepsilon}}^{m+\Delta m}
$$

Here, $\bar{\sigma}$ denotes the effective stress, $\bar{\varepsilon}$ denotes the effective strain, $K$ denotes the strength coefficient, and $n$ denotes the strain hardening exponent. The effect of $\Delta m$ on the stress-strain curve depends on the range of $\dot{\bar{\varepsilon}}$. If $\Delta m>0$, the magnitude of the stress for the same strain decreases at $\dot{\bar{\varepsilon}}<1$, and the magnitude of the stress for the same strain increases at $\dot{\bar{\varepsilon}} \geq 1$. If $\Delta m<0$, the opposite trend occurs. 


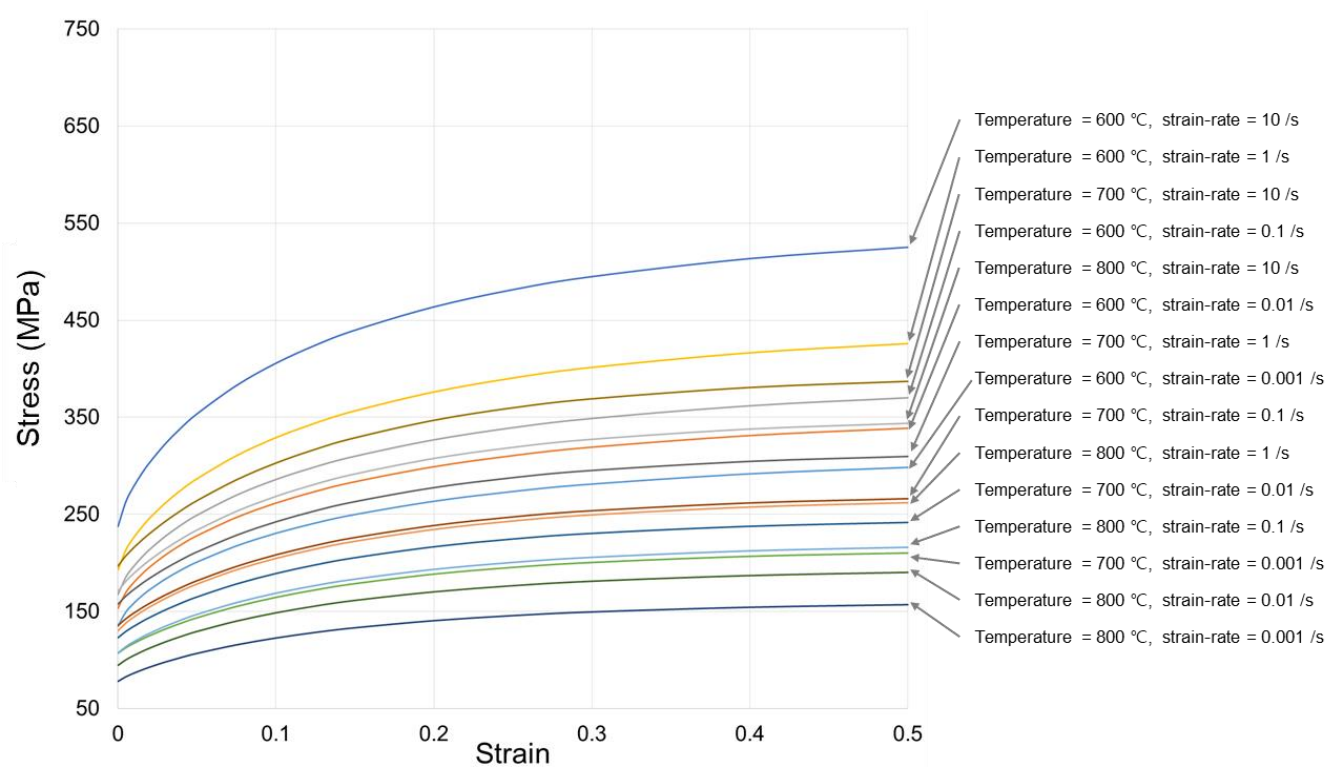

Figure 9. Stress-strain curve of 22MnB5 material used for hot stamping forming analysis.

The flow stress of the material at $700{ }^{\circ} \mathrm{C}$ was experimentally measured under three strain-rate conditions of $0.006,0.011$, and $0.017 / \mathrm{s}$. Based on the rate power law approximation of $\bar{\sigma} \approx K K_{\bar{\varepsilon}}^{\prime m}$ at high temperatures, the value of strain-rate sensitivity was estimated to be about 0.16 . For 850,900 , and 950 , which we assumed as the initial temperature of the sheet for B-pillar forming analysis, this value became a reference.

Following this, forming analysis was performed within an appropriate range of the process and material variables, and the change in formability was quantitatively evaluated.

Among the process and material variables, the initial thickness of the sheet is useful for examining problems that arise when the manufactured sheet is smaller than the standard dimension or when a sheet thinner than the original thickness is used. If the thickness of the sheet is larger than the original thickness of $1.95 \mathrm{~mm}$ in the given die clearance conditions, problems may occur due to excessive compression due to contact with the die. Therefore, 1.8, 1.95, and $2.1 \mathrm{~mm}$, which are smaller than or equal to $1.95 \mathrm{~mm}$, were selected as the test values. Table 4 shows the values of the process and material variables investigated in this study.

Table 4. Values of process and material variables considered for evaluating the effect on formability.

\begin{tabular}{ccc}
\hline Process and Material Variable & Unit & Values Applied to Forming Analysis \\
\hline Initial thickness of sheet & $\mathrm{mm}$ & $1.8,1.95,2.1$ \\
Initial temperature of sheet & ${ }^{\circ} \mathrm{C}$ & $850,900,950$ \\
Friction coefficient & - & $0.2,0.3,0.4$ \\
Strain rate sensitivity $\Delta m$ & $1 / \mathrm{s}$ & $0,0.1,0.2$ \\
\hline
\end{tabular}

In order to evaluate the reliability of the forming analysis, the measured values of the thickness strain in Section 2a of the B-pillar presented in the Numisheet 2008 benchmark results were compared with the values predicted based on the forming analysis shown in Figure 10. Comparing the results of the thickness strain, the measured value and the predicted value seemed to be similar to each other. Considering the complexity of the actual automotive parts, since the difference between the actual product measurement and the forming analysis prediction is acceptable, it was considered reasonable to evaluate the effect of process and material variables based on the forming analysis result. 

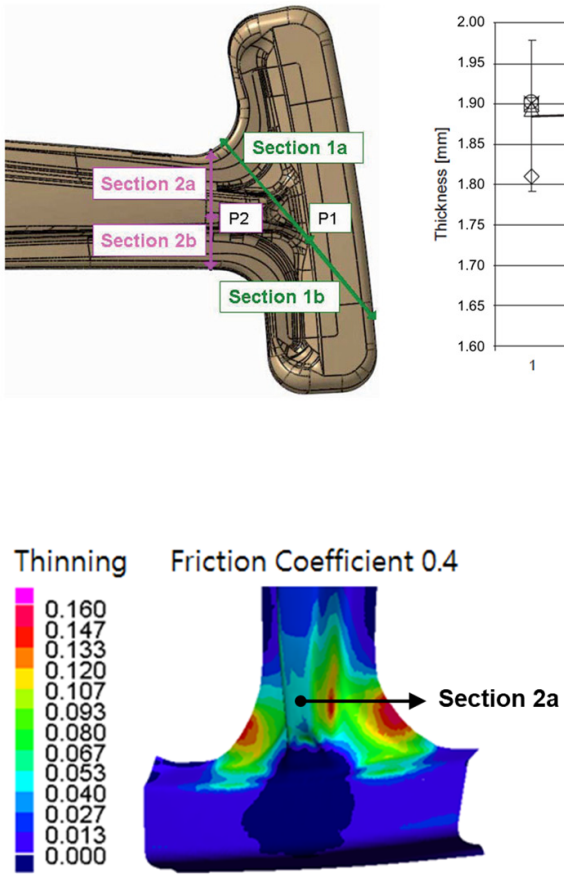

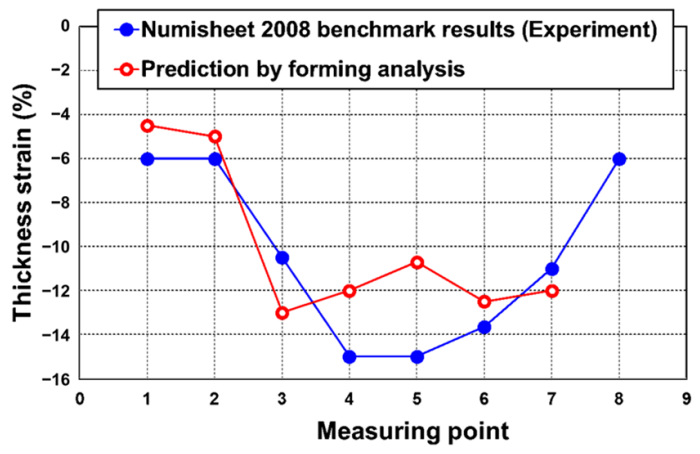

(b)

Figure 10. (a) Thickness in Section 2a of the B-pillar from the Numisheet 2008 benchmark results; (b) thickness strain in Section 2a from the forming analysis compared with the Numisheet 2008 benchmark results.

For the thickness strain of the sheet blank, a location where the deformation of the blank is large was selected. For the martensite phase ratio, a position where the martensite phase transformation does not sufficiently occur when contact with the die is insufficient in the hot stamping process was selected [10]. The final locations selected for measurement of the thickness strain and the martensite phase ratio are shown in Figure 11.

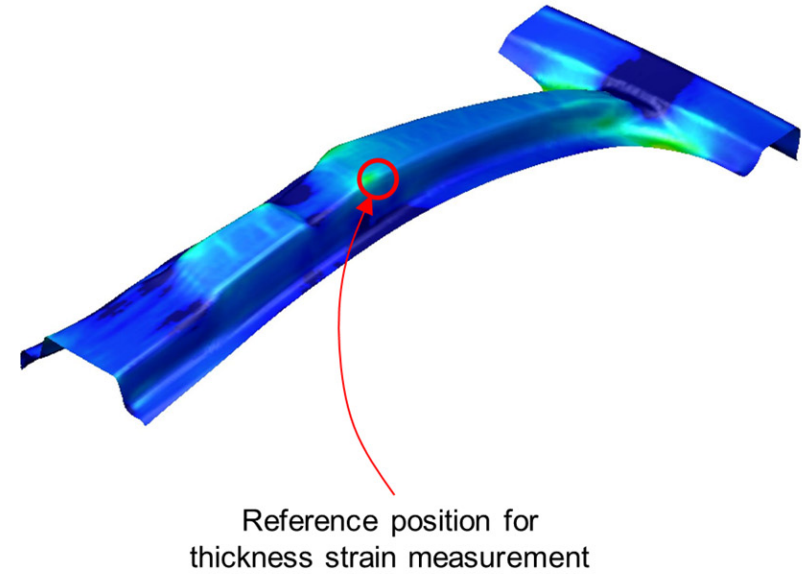

(a)

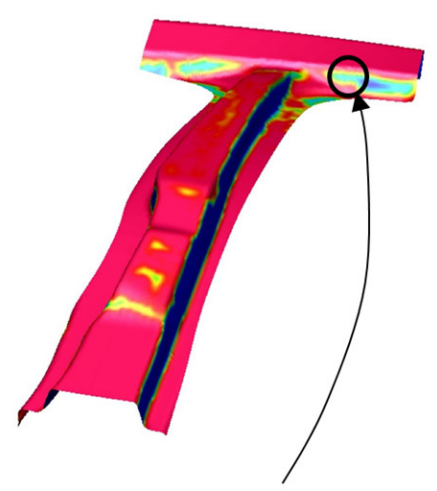

Reference position for martensite phase ratio measurement

(b)

Figure 11. Reference positions for comparing (a) thickness strain and (b) martensitic phase ratio in B-pillar parts. 


\section{Evaluation of the Effect of Process and Material Variables Based on Hot Stamping Forming Analysis}

The results of forming analysis according to changes in process and material variables were analyzed using Minitab, and the effects of sheet blank initial temperature, sheet blank initial thickness, friction coefficient, and strain-rate sensitivity on thickness strain are shown in Figure 12. In addition, the effects of the initial temperature of the sheet blank, the initial thickness of the sheet blank, the friction coefficient, and the strain-rate sensitivity on the martensite phase ratio are shown in Figure 13, respectively.
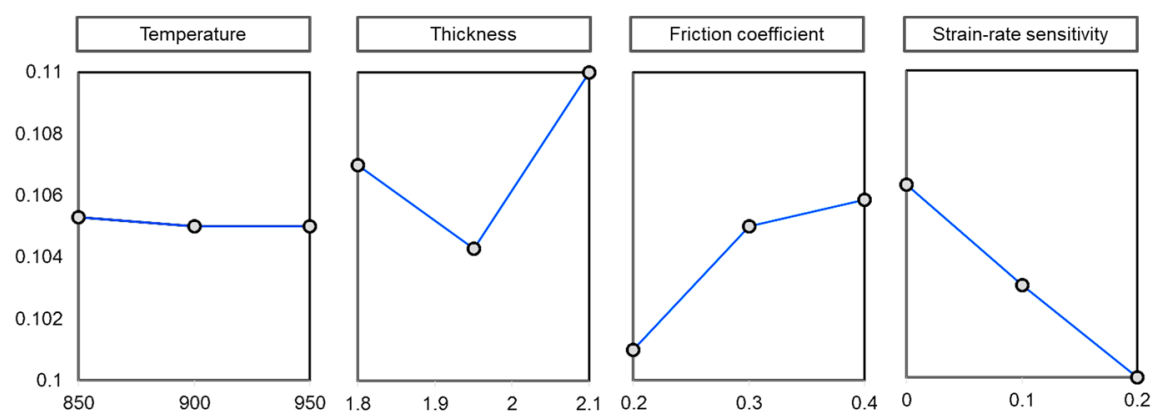

Figure 12. Effects of temperature, thickness, friction coefficient, and strain-rate sensitivity on thickness strain (main effects plot from Minitab).

\subsection{Variable 1: Effect of the Initial Temperature of the Sheet Blank}

From Figure 12, it can be seen that as the initial temperature of the sheet increases, the thickness strain decreases very slightly. That is, if the fracture is dependent on the thickness strain, higher temperatures appear to be slightly more beneficial in delaying the fracture.
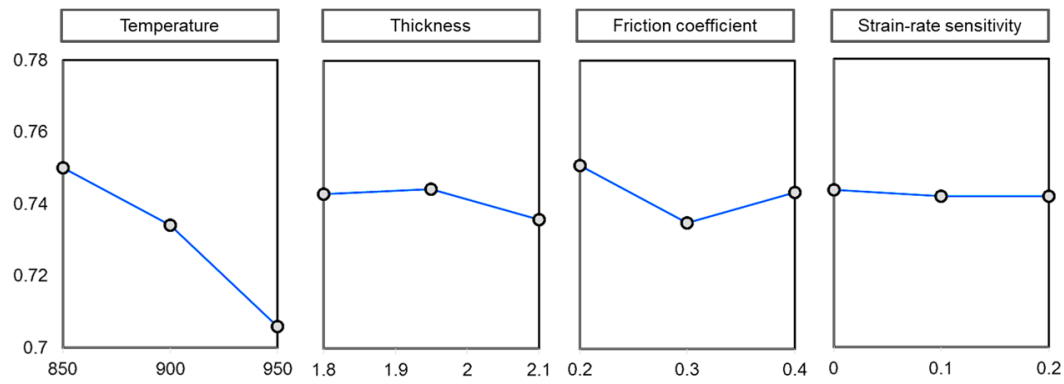

Figure 13. Effects of temperature, thickness, friction coefficient, and strain-rate sensitivity on martensite phase ratio (main effects plot from Minitab).

On the other hand, in the hot stamping test results for the T-type part, it was observed that fracture occurs at a deeper drawing depth as the heating temperature increases. That is, the higher temperature was advantageous in increasing the forming limit of the T-type part. This tendency of increasing the forming limit as the temperature increases is consistent with the results presented in previous studies $[15,16]$. Therefore, it can be seen that the prediction results for B-pillar are consistent with the results presented in T-type experiments and previous studies.

From Figure 13, it can be seen that the martensite phase ratio tends to decrease as the initial temperature of the sheet increases. As a result, it was predicted that the highest martensite phase ratio could be obtained at $850^{\circ} \mathrm{C}$.

Referring to the results of previous studies on the martensite phase ratio according to the initial temperature of the sheet, Zhang et al. argued that the best option for the initial temperature of the sheet was $850^{\circ} \mathrm{C}$ [37]. In addition, M. Naderi and W. Bleck argued that as the sheet heating temperature increases, the optimum sheet heating temperature for martensite phase ratio is $800-850{ }^{\circ} \mathrm{C}$ [38]. 
After the sheet is heated to a specified temperature in the furnace, some degree of cooling may occur for a period of time due to transport and waiting until hot stamping starts. Therefore, at the start of hot stamping, the temperature may be slightly lower than that mentioned in previous studies. Considering the fact that the initial temperature of sheet defined in this study means the temperature at which hot stamping starts, it can be seen that the $850{ }^{\circ} \mathrm{C}$ predicted as the optimal temperature based on the martensite phase ratio and the optimal temperature range $\left(800-850^{\circ} \mathrm{C}\right)$ of the previous study correspond with each other.

However, the martensite phase ratio may be affected not only by the temperature of the sheet, but also by the effect of die quenching due to contact between the die and the sheet blank. Therefore, it is considered that the optimal sheet blank temperature for the martensite phase ratio can be determined by reflecting various other variables such as the shape of the part, die design, and process sequence.

\subsection{Variable 2: Effect of Sheet Thickness}

The effect of the initial thickness of the sheet on the thickness strain seems to be slightly complicated. In this case, the thickness strain of the sheet was measured instead of the fracture of the sheet. Even if the thickness strain of the sheet is the same, the actual probability of fracture may be different if the temperature of the material is different. Specifically, from the test results of the previous T-type part, it could be seen that in the case of a thick sheet, the fracture occurred at a larger drawing depth. As the result of the T-type test, the thick sheet blank has a larger heat capacity than the thin sheet blank, so cooling can proceed slowly. Thus, if the temperature of the sheet blank, which is heated to the same initial temperature and then undergoes the stamping and die quenching processes, is compared at a certain point in the process, the temperature may be higher in a thick sheet than in a thin sheet. As already mentioned in the effect of the initial temperature of the sheet, when the temperature of sheet blank is higher, the fracture drawing depth in the T-type test is larger.

Studies by Li et al. [15] and Li et al. [16] also showed that the forming limit was larger when the sheet temperature was higher. Furthermore, the temperature could be higher in the thicker sheet. From these two facts, it can be inferred that as the initial thickness of the sheet blank increases, the actual forming limit in terms of fracture may increase even if the thickness strain does not change.

Additionally, it seems that the martensite phase ratio decreases as the initial thickness of the sheet blank increases. The clearance of the stamping die was set to $1.95 \mathrm{~mm}$ in consideration of the thickness of the sheet blank. Since the thickness of the sheet decreases due to the stretching of the sheet during forming, a clearance of $1.95 \mathrm{~mm}$ does not interfere with the normal forming process. At this time, if the initial thickness of the sheet blank is reduced, the contact area or contact surface pressure between the stamping die and the sheet blank decreases in the forming process, which may reduce the die quenching effect. This can cause a decrease in the martensite phase ratio. However, as mentioned in the analysis of the T-type test results, the thinner the sheet, the lower the heat capacity of the sheet, which may increase the cooling rate during the stamping or die quenching process. This can cause an increase in the martensite phase ratio. That is, when the thickness of the sheet blank decreases, these two opposite effects can occur. From the results in Figure 13, it is predicted that the martensite phase ratio will slightly increase when the thickness of the sheet blank is smaller than $1.95 \mathrm{~mm}$. That is, in the thickness range of $1.8-2.1 \mathrm{~mm}$, it can be inferred that the increase in the cooling rate due to the decrease in the thickness is superior to the decrease in the die quenching effect due to the decrease in the contact area or the contact surface pressure. However, the values of the martensite phase ratio for the thicknesses of $1.8 \mathrm{~mm}$ and $2.1 \mathrm{~mm}$ are 0.743 and 0.736 , respectively, and there was no significant difference.

When the martensite phase ratio was measured at all positions of the B-pillar part, it was found that the position with the minimum martensite phase ratio changed slightly 
according to the change in the thickness of the sheet blank. For two B-pillar parts formed using sheet blanks of two thicknesses, $1.8 \mathrm{~mm}$ and $2.1 \mathrm{~mm}$, the position and minimum value of the martensite phase ratio at the moment of $30 \mathrm{~s}$ after stamping and die quenching were compared in Figure 14. Although the difference is insignificant, it can be seen that the minimum value of the martensite phase ratio on the entire area of the part is slightly larger for the part from thickness of $1.8 \mathrm{~mm}$ than for the part from thickness of $2.1 \mathrm{~mm}$.

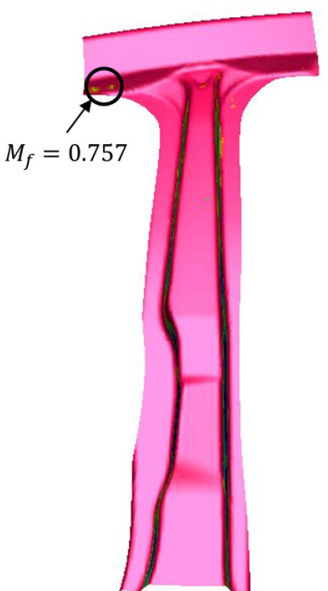

(a)

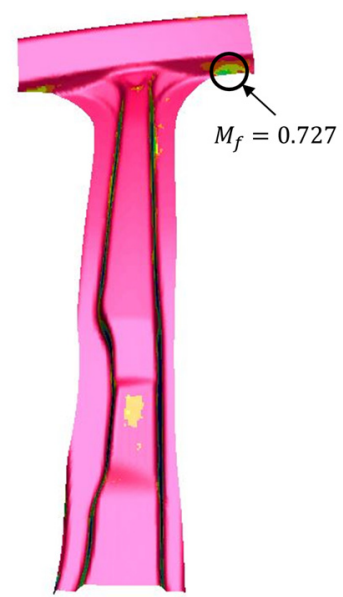

(b)

Figure 14. The position and minimum value of the martensite phase ratio at $30 \mathrm{~s}$ after stamping and die quenching for (a) part from sheet blank thickness of $1.8 \mathrm{~mm}$ and (b) part from sheet blank thickness of $2.1 \mathrm{~mm}$.

\subsection{Variable 3: Effect of Friction Coefficient}

As the friction coefficient increased, the thickness strain of the sheet increased. It is because the inflow of the sheet blank was easier when the friction coefficient was larger.

Hot stamping is a high temperature forming process, and it is generally known that the value of the friction coefficient is larger in high temperature forming than in room temperature forming [39-43]. Depending on the lubrication and the type of coating, the friction coefficient in hot stamping is distributed from 0.4 to 0.6 , and in severe cases, a value of 0.8 or more may appear [44]. On the other hand, in room temperature forming, the friction coefficient can usually show a value slightly larger than 0.1 . Therefore, the friction coefficients in the range of 0.2-0.4 investigated in this study can be regarded as reasonable values for the actual hot stamping process.

In high temperature forming such as hot stamping, large friction coefficient as well as thermal fatigue and wear of die surface can cause problems during the forming process. Therefore, the use of suitable coatings or lubricants may be essential.

On the other hand, unlike the large effect on the thickness strain, the effect of the friction coefficient on the martensite phase ratio was found to be small.

\subsection{Variable 4: Effect of Strain-Rate Sensitivity}

As the value of strain-rate sensitivity increases, the thickness strain of the sheet decreases. This is a result consistent with the basic plasticity theory that a material with a large strain-rate sensitivity has a greater resistance to thickness reduction or necking [45]. On the other hand, unlike the effect on the thickness strain, the effect of the strain-rate sensitivity on the martensite phase ratio was found to be small.

\subsection{Summary}

In summarizing the results, the effect of the variable on the thickness strain was large in the order of the die-blank friction coefficient, the strain-rate sensitivity of the material, the initial temperature of the sheet blank, and the initial thickness of the sheet 
blank. Additionally, the effect of the variable on the martensite phase ratio was large in the order of the initial temperature of the sheet blank, the initial thickness of the sheet blank, the strain-rate sensitivity of the material, and the die-blank friction coefficient. The effect of the initial temperature of sheet blank and the initial thickness of sheet blank on the thickness strain can be considered to be small, and the effect of the strain-rate sensitivity of the material and the die-blank friction coefficient on the martensite phase ratio can be considered small.

In the forming of mass-produced body parts such as the B-pillar, if fractures occur during forming, the desired product cannot be manufactured. In addition, the B-pillar is a part to protect the driver when a vehicle collision accident occurs. So, if the martensite phase ratio required for high strength enhancement through hot stamping cannot be obtained, a problem may occur in vehicle safety. For this reason, if a problem occurs in formability such as thickness strain and martensite phase ratio, it is necessary to correct the problem by appropriately modifying process and material variables. That is, the sensitivity of formability to process and material variables can be used to estimate the amount of increase or decrease in variables.

An example of how to change each variable is as follows. The initial temperature of the sheet blank can be changed by setting the heating temperature in the furnace. The initial thickness of the sheet blank can be changed easily by changing the specifications of the sheet. Meanwhile, the friction coefficient can be appropriately reduced by using a lubricant suitable for the hot stamping process, lowering the die surface roughness, or coating the die or sheet surface. For material variables such as strain-rate sensitivity, appropriate material processing may be required to change the material variable to a desired value. In general, the behavior of the grain boundary has a large effect on the strain-rate sensitivity value at high temperature. Since the volume fraction and activity of grain boundaries can vary depending on grain size, severe plastic deformation for grain refinement can be used to change strain-rate sensitivity. In addition, the strain-rate sensitivity can be changed by controlling the alloy composition that affects the grain refinement and work hardening behavior during deformation.

\section{Conclusions}

This study aims to quantitatively identify the effect of process and material variables on formability in the hot stamping process of actual automotive parts and optimize the hot stamping mass production process through this. In this study, the criterion of "formability" was defined as a concept that includes both "thickness strain", which indicates whether the desired shape can be formed without fracture, and "martensite phase ratio", which indicates whether the desired strength can be achieved. B-pillar, a representative automotive body part, was selected as the target part to be investigated in this study.

In order to understand the fracture behavior according to the temperature and thickness of the sheet, a forming test was performed on a T-type part that simplified the B-pillar part. In addition, the effect of process and material variables on hot stamping formability for the B-pillar part was analyzed through finite element analysis. The effect of variables was quantified based on the results of finite element analysis. The results were as follows.

(1) T-type forming was performed by changing the initial temperature and initial thickness of the sheet blank. As a result, the higher the initial temperature of the sheet blank and the larger the initial thickness of the sheet blank, the fracture occurred at a greater depth of drawing. That is, as the initial temperature and initial thickness of the sheet blank increased, the forming limit of the sheet blank increased.

(2) The hot stamping analysis of B-pillar parts was performed by changing four processes and material variables: the initial temperature of the sheet blank, the initial thickness of the sheet blank, the die-blank friction coefficient, and the strain-rate sensitivity of the material. As a result, the effect of the variable on the thickness strain of the formed part was in the order of the die-blank friction coefficient, the strain-rate sensitivity of the material, the initial sheet blank temperature, and the initial sheet 
blank thickness. Additionally, the effect of the variable on the martensite phase ratio of the formed part was in the order of the initial temperature of the sheet blank, the initial thickness of the sheet blank, the strain-rate sensitivity of the material, and the die-blank friction coefficient.

(3) Formability in this study is a concept that includes both the thickness strain and the martensite phase ratio of the formed part. Among them, in terms of thickness strain, the formability is excellent when the forming limit is high and fracture does not easily occur. Additionally, in terms of the martensite phase ratio, the formability is excellent when the strength of the formed part increases due to sufficient phase transformation into martensite during the stamping process. If the formability of a product is not sufficiently excellent under the conditions of a given process and material variable, it will be possible to improve the formability by changing the variable as much as necessary based on the sensitivity of formability to process and material variables. In the case of material variables, the strain-rate sensitivity of material may be altered by changing the alloy composition of the original material or by changing the grain size through appropriate plastic working.

This study presented a practical approach for optimizing the hot stamping process of mass-produced automotive body parts. Compared to simple model parts at laboratory level, actual automotive body parts are difficult to optimize due to the shape and complexity of the process. Although the B-pillar was investigated as a representative part, this study identified and quantified the major variables affecting formability among various process and material variables. The results of this study will be applicable to the optimization of the hot stamping process of other automotive body parts.

Author Contributions: Conceptualization, H.-K.K.; methodology, H.-K.K.; software, K.H.Y.; validation, K.H.Y. and H.-K.K.; formal analysis, K.H.Y.; investigation, K.H.Y.; resources, K.H.Y.; data curation, K.H.Y.; writing-original draft preparation, K.H.Y.; writing—review and editing, H.-K.K.; visualization, K.H.Y.; supervision, H.-K.K.; project administration, H.-K.K.; funding acquisition, H.-K.K. Both authors have read and agreed to the published version of the manuscript.

Funding: This research was funded by the basic research program of the Ministry of Science and ICT (NRF-2020R1F1A1066221) and the R\&D Convergence Program of NST (National Research Council of Science \& Technology) of the Republic of Korea. This research was also funded by BK21 Program (5199990814084) through the National Research Foundation of Korea (NRF) funded by the Ministry of Education.

Institutional Review Board Statement: Not applicable.

Informed Consent Statement: Not applicable.

Data Availability Statement: Data available in a publicly accessible repository.

Acknowledgments: We would like to acknowledge Hyundai Steel for financial support for this investigation.

Conflicts of Interest: The authors declare no conflict of interest.

\section{References}

1. Mori, K.; Maki, S.; Tanaka, Y. Warm and hot stamping of ultra high tensile strength steel sheets using resistance heating. CIRP Ann. 2005, 54, 209-212. [CrossRef]

2. Merklein, M.; Lechler, J.; Geiger, M. Characterization of the flow properties of the quenchenable ultra high strength steel $22 \mathrm{MnB5}$. CIRP Ann. 2006, 55, 229-232. [CrossRef]

3. Bariani, P.F.; Bruschi, S.; Ghiotti, A.; Turetta, A. Testing formability in the hot stamping of HSS. CIRP Ann. 2008, 57, 265-268. [CrossRef]

4. Karbasian, H.; Tekkaya, A.E. A review on hot stamping. J. Mater. Process. Technol. 2010, 210, 2103-2118. [CrossRef]

5. Abdulhay, B.; Bourouga, B.; Dessain, C. Experimental and theoretical study of thermal aspects of the hot stamping process. Appl. Therm. Eng. 2011, 31, 674-685. [CrossRef]

6. Turetta, A.; Bruschi, S.; Ghiotti, A. Investigation of 22MnB5 formability in hot stamping operations. J. Mater. Process. Technol. 2006, 177, 396-400. [CrossRef] 
7. Shao, Z.; Li, N.; Lin, J.; Dean, T. Formability evaluation for sheet metals under hot stamping conditions by a novel biaxial testing system and a new materials model. Int. J. Mech. Sci. 2017, 120, 149-158. [CrossRef]

8. Dahan, Y.; Chastel, Y.; Duroux, P.; Hein, P.; Massoni, E.; Wilsius, J. Formability investigations for the hot stamping process. In Proceedings of the International Deep Drawing Research Group (IDDRG) International Conference, Porto, Portugal, $19-21$ June 2006.

9. Kusumi, K.; Maki, J.; Nomura, N. Formability and FEM simulation of steel sheets in the hot stamping process. Nippon Steel Tech. Rep. 2013, 103, 47-54.

10. Windmann, M.; Röttger, A.; Theisen, W. Formation of intermetallic phases in Al-coated hot-stamped 22MnB5 sheets in terms of coating thickness and Si content. Surf. Coat. Technol. 2014, 246, 17-25. [CrossRef]

11. Gorriño, A.; Angulo, C.; Muro, M.; Izaga, J. Investigation of Thermal and Mechanical Properties of Quenchable High-Strength Steels in Hot Stamping. Metall. Mater. Trans. B 2016, 47, 1527-1531. [CrossRef]

12. Gui, Z.X.; Liang, W.K.; Liu, Y.; Zhang, Y.S. Thermo-mechanical behavior of the Al-Si alloy coated hot stamping boron steel. Mater. Des. 2014, 60, 26-33. [CrossRef]

13. Kim, H.K.; Lee, S.H.; Choi, H. Evaluation of Contact Heat Transfer Coefficient and Phase Transformation during Hot Stamping of a Hat-Type Part. Materials 2015, 8, 2030-2042. [CrossRef]

14. Dilmec, M.; Halkaci, H.S.; Ozturk, F. Effects of sheet thickness and anisotropy on forming limit curves of AA2024-T4. Int. J. Adv. Manuf. Technol. 2013, 67, 2689-2700. [CrossRef]

15. Li, H.; Wu, X.; Li, G. Prediction of Forming Limit Diagrams for 22MnB5 in Hot Stamping Process. J. Mater. Eng. Perform. 2013, 22, 2131-2140. [CrossRef]

16. Li, F.F.; Fu, M.W.; Lin, J.P. Experimental and theoretical study on the hot forming limit of 22MnB5 steel. Int. J. Adv. Manuf. Technol. 2014, 71, 297-306. [CrossRef]

17. Yao, D.; Cai, L.; Bao, C. A new fracture criterion for ductile materials based on a finite element aided testing method. Mater. Sci. Eng. A 2016, 673, 633-647. [CrossRef]

18. Churyumov, A.Y.; Medvedeva, S.V.; Mamzurina, O.I.; Kazakova, A.A.; Churyumova, T.A. United Approach to Modelling of the Hot Deformation Behavior, Fracture, and Microstructure Evolution of Austenitic Stainless AISI 316Ti Steel. Appl. Sci. 2021, 11, 3204. [CrossRef]

19. Kubík, P.; Šebek, F.; Hůlka, J.; Petruška, J. Calibration of ductile fracture criteria at negative stress triaxiality. Int. J. Mech. Sci. 2016, 108-109, 90-103. [CrossRef]

20. Kim, H.K.; Kim, W.J. Failure prediction of magnesium alloy sheets deforming at warm temperatures using the Zener-Holloman parameter. Mech. Mater. 2010, 42, 293-303. [CrossRef]

21. Jeon, Y.J.; Song, M.J.; Kim, H.K.; Cha, B.S. Effect of hot-stamping process conditions on the changes in material strength. Int. J. Automot. Technol. 2015, 16, 619-627. [CrossRef]

22. Kusumi, K.; Nomura, N.; Yamamoto, S.; Nakata, M.; Abe, M.; Suehiro, M. Improvement of Cylindrical Deep Drawability in Hot Stamping. Procedia Eng. 2014, 81, 1719-1724. [CrossRef]

23. Marciniak, Z.; Duncan, J.L.; Hu, S.J. Mechanics of Sheet Metal Forming; Butterworth-Heinemann: Oxford, UK, $2002 ;$ p. 75.

24. Llewellyn, D.; Hudd, R. Steels: Metallurgy and Applications, 3rd ed.; Butterworth-Heinemann: Oxford, UK, $1998 ;$ p. 28.

25. Dahan, Y.; Chastel, Y.; Duroux, P.; Wilsius, J.; Hein, P. Procedure for the Experimental Determination of a Forming Limit Curve for Usibor 1500 P. In Proceedings of the International Deep Drawing Research Group (IDDRG) International Conference, Györ, Hungary, 21-23 May 2007.

26. Cao, J.; Yao, H.; Karafillis, A.; Boyce, M.C. Prediction of localized thinning in sheet metal using a general anisotropic yield criterion. Int. J. Plast. 2000, 16, 1105-1129. [CrossRef]

27. Sarkar, B.; Jha, B.K.; Mukerjee, D.; Jha, S.; Narasimhan, K. Thinning as a failure criterion during sheet metal forming. Pract. Fail. Anal. 2002, 2, 63-64. [CrossRef]

28. Zhang, C.; Leotoing, L.; Guines, D.; Ragneau, E. Theoretical and numerical study of strain rate influence on AA5083 formability. J. Mater. Process. Technol. 2009, 209, 3849-3858. [CrossRef]

29. Khan, A.S.; Baig, M. Anisotropic responses, constitutive modeling and the effects of strain-rate and temperature on the formability of an aluminum alloy. Int. J. Plast. 2011, 27, 522-538. [CrossRef]

30. Romhanji, E.; Dudukovska, M.; Glišić, D. The effect of temperature on strain-rate sensitivity in high strength Al-Mg alloy sheet. J. Mater. Process. Technol. 2002, 125-126, 193-198. [CrossRef]

31. Simon, P.; Demarty, Y.; Rusinek, A.; Voyiadjis, G.Z. Material Behavior Description for a Large Range of Strain Rates from Low to High Temperatures: Application to High Strength Steel. Metals 2018, 8, 795. [CrossRef]

32. Tomáš, M.; Evin, E.; Kepič, J.; Hudák, J. Physical Modelling and Numerical Simulation of the Deep Drawing Process of a Box-Shaped Product Focused on Material Limits Determination. Metals 2019, 9, 1058. [CrossRef]

33. Vrolijk, M.; Lorenz, D.; Porzner, H.; Holecek, M. Supporting lightweight design: Virtual modeling of hot stamping with tailored properties and warm and hot formed aluminium. Procedia Eng. 2017, 183, 336-342. [CrossRef]

34. Hora, P.; Volk, W.; Roll, K.; Griesbach, B.; Kessler, L.; Hotz, W. The Numisheet 2008 Benchmark Study Part B; Numisheet 2008 Organizing Committee: ETH Zurich, Switzerland, 2008; pp. 115-129.

35. Bosetti, P.; Bruschi, S.; Stoehr, T.; Lechler, J.; Merklein, M. Interlaboratory comparison for heat transfer coefficient identification in hot stamping of high strength steels. Int. J. Mater. Form. 2010, 3, 817-820. [CrossRef] 
36. Liu, X.; Gharbi, M.M.; Manassib, O.; Fakir, O.E.; Wang, L. Determination of the interfacial heat transfer coefficient between AA7075 and different forming tools in hot stamping processes. Procedia Eng. 2017, 207, 717-722. [CrossRef]

37. Zhang, P.; Zhu, L.; Xi, C.; Luo, J. Study on Phase Transformation in Hot Stamping Process of USIBOR ${ }^{\circledR} 1500$ High-Strength Steel. Metals 2019, 9, 1119. [CrossRef]

38. Naderi, M.; Bleck, W. An investigation into martensitic transformation in hot stamping process. Wit. Trans. Eng. Sci. 2007, 57, 95-104.

39. Yanagida, A.; Azushima, A. Evaluation of coefficients of friction in hot stamping by hot flat drawing test. CIRP Ann. 2009, 58, 247-250. [CrossRef]

40. Sasaki, H.; Mukai, T.; Yanagida, A. Measurement of coefficient of friction in hot stamping by hot deep drawing test. Key Eng. Mat. 2016, 716, 184-189. [CrossRef]

41. Uda, K.; Azushima, A. Effect of Die Surface Coating on Coefficient of Friction in Hot Stamping of Aluminum-coated High-Strength Steel. J. Jpn. Soc. Technol. Plast. 2014, 55, 132-136. [CrossRef]

42. Geiger, M.; Merklein, M.; Lechler, J. Determination of tribological conditions within hot stamping. Prod. Eng. 2008, 2, 269-276. [CrossRef]

43. Li, G.; Long, X.; Yang, P.; Liang, Z. Advance on friction of stamping forming. Int. J. Adv. Manuf. Technol. 2018, 96, 21-38. [CrossRef]

44. Pelcastre, L. Hot Forming Tribology: Galling of Tools and Associated Problems. Licentiate Thesis, Luleå University of Technology, Luleå, Sweden, 2011.

45. Hosford, W.F.; Caddell, R.M. Metal Forming: Mechanics and Metallurgy, 3rd ed.; Cambridge University Press: Cambridge, UK, 2007; pp. 52-72. 